\title{
Residual Stress and Deformation Analysis in Machining Split Straight Bevel Gears
}

\author{
Bin Wang 1,2 - Chenxiao Yan ${ }^{1}$ * - Jubo Li ${ }^{1}$ - Peiyao Feng ${ }^{3}$ - Shuaipu Wang ${ }^{1}$ - Shuo Chen ${ }^{1}-$ Jianxin $\mathrm{Su}^{1}$ \\ ${ }^{1}$ Henan University of Science and Technology, School of Mechatronics Engineering, China \\ ${ }^{2}$ Collaborative Innovation Center of Machinery Equipment Advanced Manufacturing, China \\ ${ }^{3}$ Xinxiang Aviation Industry (Group) Co., China
}

In the machining of split straight bevel gears, the stiffness changes and internal stress are redistributed, which leads to serious deformation of the gear blank after machining. To rectify this problem, q finite element model is established by transforming the processing information of the gear blank into the finite element simulation calculation information, and the gear machining simulation of split straight bevel gear is carried out. Considering the material, design, and machining process of the gear blank, the characteristics and laws of internal stress variation during the gear machining are studied, and the internal mechanism and deformation law of split straight bevel gear are explored. Finally, the gear machining experiment, and the gear blank measurement are carried out. The results show that the deformation law of simulation is consistent with that of the experiment and the deformation characteristics of the split straight bevel gear are consistent with the change law of initial residual stress.

Keywords: split straight bevel gear, residual stress, machining deformation, finite element model, deformation measurement

Highlights

- The finite element model for deformation prediction of the split straight bevel gear is established, and the results of finite element calculation are in good agreement with the experimental results.

- In the process of gear cutting, the change of initial residual stress near the upper and lower surfaces is the greatest, and the change and redistribution of stress is independent of the cutting tooth sequence.

- In the inner of the machined tooth, the tensile and compressive stress in the X-direction decreases significantly, while the stress in the Y-direction changes little. The performance and change of Z-direction stress in the whole machining process are relatively minor.

- The Z-direction bending deformation in the middle of split straight bevel gear is the largest, the deformation at the outer is larger than that at the inner, and the difference of deformation between the outer and inner is especially obvious in the middle.

- The X-direction deformation of the split straight bevel gear basically does not change in the face-width direction, and the closer to the middle of length direction, the smaller the deformation is.

- The deformation in Y-direction is smaller in the middle position, the deformation is slightly different in the face-width direction, and the deformation at wider end of a single tooth (an outer) is slightly greater than that at (the narrower end of a single tooth (an inner).

\section{O INTRODUCTION}

An oversize straight bevel gear is one of the most important parts in large-scale heavy industrial equipment. It is widely used in mining, power generation and other important fields. An extra-large bevel gear (wheel, diameter greater than $3000 \mathrm{~mm}$ ) requires a higher forming method and machining equipment, and its manufacturing cost is high, its manufacturing cycle is long, and its machining is very difficult [1] and [2]. The structural stiffness of the entire oversize straight bevel gear is small and is easily deformed during machining and assembly, and the machining is often limited by the size of the equipment. Therefore, the existing extra-large straight bevel gear mostly uses a split structure [3] and [4]. According to the engineering practice and existing research data, the bending deformation of the split straight bevel gear is the most obvious after machining, which can reach several millimetres [5] and [6]. The deformation of the split gear blank mainly depends on two aspects: one is the deformation created by the stiffness change and internal stress caused by material removal, which accounts for $92.2 \%$ of the total deformation [7] to [9], and the structural deformation caused by surface stress, which only accounts for $7.8 \%$ [10] and [11]. Therefore, this paper focuses on the study of machining deformation caused by the change of internal stress, and the influence of surface processing stress, cutting heat, and workpiece clamping on the deformation is not studied. The oversize straight bevel gear is divided first, and then the teeth are cut. In existing engineering practice, there is a lack of effective theoretical guidance, which leads to great blindness and randomness. 
Regarding the machining deformation of largescale parts, the existing research mainly focuses on the numerical control machining deformation, deformation mechanism and deformation prediction of aviation structure components, frame-shaped components and ring form thin-walled components. Based on theoretical calculation and finite element simulation, Sun and Ke [12] studied the influence of the initial internal stress on the machining deformation of large whole components. $\mathrm{Wu}$ [13] explored the machining deformation principle of thin-walled components from the machining principle and finite element simulation. Lu [14] comprehensively considered the effects of initial internal stress, machining stress, temperature change and clamping stress on the deformation of frame-shaped integral components and established a deformation prediction model. Cheng et al. [7] aimed at the milling deformation behaviour of aviation frame-shaped integral components, based on the restart analysis principle, the milling process was simulated, and a calculation system was established. Zhou [15] established a finite element model to predict the deformation of ring thin-walled components, analysed the influence of machining stress on machining accuracy, and predicted the relationship between the amount of material removed and machining error. Huang [16] used theoretical calculation to analyse the stiffness change, internal stress distribution and deformation during machining, and established the deformation prediction model of integral components. Nervi [17] established a machining deformation prediction model of components with initial internal stress and analysed the relationship between the distribution of initial internal stress and the deformation. Wu et al. [18] put forward a quasi-symmetric machining method to reduce the deformation by using the M-symmetry distribution law of residual stress. The deformation mechanism of milling residual stress is studied and compared with the finite element method. Zhang et al. [19] analysed the welding sequence, stress distribution and deformation of vacuum vessels and carried out finite element modelling. Keith [20] studied the influence of machining stress on the machining deformation of components. Ratchev et al. [21] established a mathematical model to predict the machining deformation of thin-walled components on the basis of a neural network, and predicted the machining error. Bremec and Kosel [22] presented an experimental determination of the buckling load and the buckling coefficient of a circular, annular plate with constant thickness, which is made of an elasticplastic hardening material.
To summarize, focusing on the machining of split straight bevel gear, this paper intends to carry out the research from the following aspects: Firstly, according to the actual distribution law of internal stress and the structural characteristics of the gear blank, the finite element modelling is carried out. Secondly, the distribution law and evolution process of the internal stress in the inner, upper and lower surface of the wheel blank were studied by simulation processing. Thereafter, the deformation forms, characteristics and evolution process of the split gear blank in machining, as well as the relationship between the deformation and machining, and the thickness of the gear blank are studied. Finally, the machining and measuring experiments of split straight bevel gear are carried out, and the finite element model and deformation analysis are verified.

\section{RESIDUAL STRESS EVOLUTION IN GEAR CUTTING}

\subsection{Finite Element Model of Split Straight Bevel Gear}

According to the existing data and stress measurement equipment in the laboratory, the aluminium alloy 7075-t7451 is to be used in the experiment of this study. The distribution of residual stress is illustrated in Fig. 1. The length direction (rolling direction) of a split gear blank is set as the $\mathrm{X}$-direction, the transverse direction is the Y-direction, from outer to inner is positive, along the thickness of gear blank is the $\mathrm{Z}$ axis, the direction is vertical upward.

Fig. 1 indicates that the residual stress curves in $\mathrm{X}$ - and Y-directions along the gear blank thickness are approximate to "M" shape, and the curves is symmetrical about the neutral axis in the thickness direction of the cross-section. There is a large compressive stress near the upper and lower surfaces of the gear blank; the maximum compressive stress in the X-direction is $-17.21 \mathrm{MPa}$ and that in Y-direction is $-13.27 \mathrm{MPa}$. The maximum tensile stress in the $\mathrm{X}$ - and Y-directions is $20 \mathrm{~mm}$ away from the middle surface of the gear blank; the maximum tensile stress in the X-direction is $16.21 \mathrm{MPa}$, and that in the Y-direction is $13.84 \mathrm{MPa}$. It should be pointed out that the large gear blank is rectangular after cutting. When the balance of three normal stress components of internal stress changes in the process of gear cutting, the dimension expansion occurs in the direction of length, width and height, but the absolute value of the change in the direction of thickness is far less than that in the direction of length and width. Simultaneously, because the cross-sectional area in the thickness direction is 
the largest, the bending stiffness is also the largest, and the deformation caused by the internal stress in the Z-direction is very small. Also, the deformation of extra-large split gear in the cutting process is at the millimetre level, so the deformation caused by internal stress in Z-direction can be ignored; therefore, this paper only analyses the internal stress in the $\mathrm{X}$ - and Y-directions.

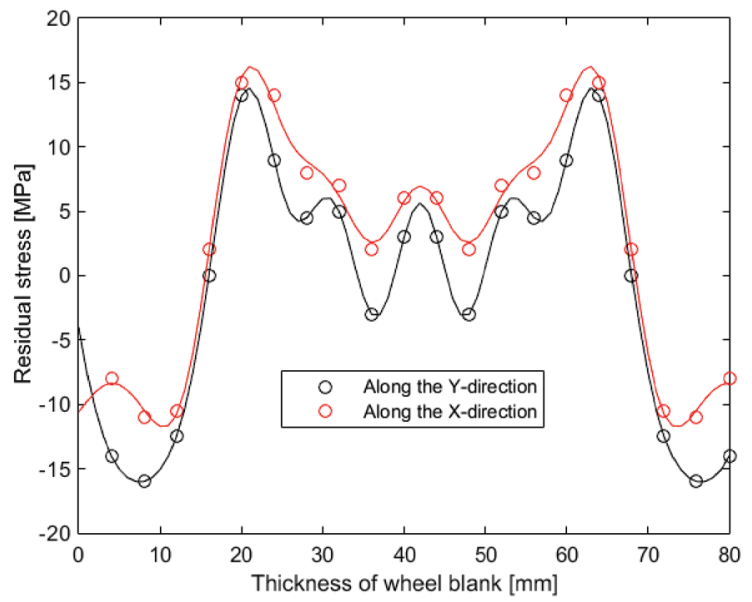

Fig. 1. Initial residual stress curve

For the wheel of extra-large straight bevel gear, the root angle is very large, the cross-section of the gear blank is approximately rectangular. Due to the large diameter and small curvature of the gear blank, and the entire gear blank is divided into several segments; each segment is similar to a cuboid. In the ABAQUS environment, the three-dimensional model of the split straight bevel gear is established according to its structural characteristics. The mesh element type is 20 node quadric hexahedral C3D20R, and the grid division is "structure". In the "grid" module, a certain number of local seeds are arranged along the thickness direction of gear blank, so the grid along the thickness direction is divided into several layers, and the thickness of each layer is $2 \mathrm{~mm}$. The rigid displacement of gear blank is limited to ensure the accuracy of simulation results. In order to obtain the machining deformation, the split gear blank must be free to deform in the simulation processing. In order to achieve the correct simulation effect, the initial stress of the gear blank material needs to be applied to the finite element model.

According to Fig. 1, the discrete data are input into MATLAB, and Fourier curve fitting is carried out. The relationship between the initial residual stress in two directions and the gear blank thickness is expressed by function respectively,

$$
\begin{aligned}
\sigma_{x}= & 0.59+\sum_{i=1}^{5} a_{i} \cos [i \cdot 0.08(z+2)] \\
& +\sum_{i=1}^{5} b_{i} \cos [i \cdot 0.08(z+2)], \\
\sigma_{y}= & 2.65+\sum_{i=1}^{4} c_{i} \cos [i \cdot 0.07(z+2)] \\
& +\sum_{i=1}^{4} d_{i} \cos [i \cdot 0.07(z+2)],
\end{aligned}
$$

in Eq. (1), $z$ is the gear blank thickness, $a_{i}, b_{i}, c_{i}, d_{i}$ are the calculated coefficients obtained by fitting.

With the function expression obtained by fitting, the SIGINI subroutine is programmed in Visual Studio with Fortran language. The SIGINI subroutine will be called by the finite element software in the calculation process to realize the automatic continuous application of the initial residual stress. The gear blank with initial internal stress $[\mathrm{MPa}]$ is shown in Fig. 2.

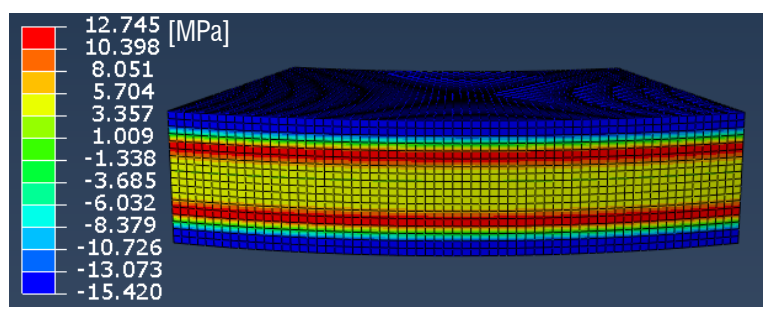

Fig. 2. Finite element model of split gear blank

After the establishment of the finite element model, the "life and death element" technology of the "interaction" module in the simulation software is used to simulate the dynamic process of cutting teeth. Firstly, the element that needs to be "killed" in the finite element model is separated from other element regions. Secondly, multiple analysis steps can be created for the processing of multiple grooves of the split wheel blank, and the removed elements can be "killed" in the corresponding analysis steps. By adjusting the unit "kill" sequence, the simulation effect of multiple cutting sequences can be achieved.

\subsection{Internal Stress Evolution in Tooth Machining}

In the finite element analysis, the module of gear is set as 20 , the number of teeth is 60 , the facewidth is $100 \mathrm{~mm}$, the thickness of the gear blank is $80 \mathrm{~mm}$, and $1 / 10$ of the circumference of the whole gear is taken as the split gear blank of the simulation. 


\subsubsection{Stress Analysis in X-direction}

Before the simulation machining, on the gear blank section in the length direction, the $\mathrm{X}$-direction stress nephogram is illustrated as Fig. 3. After the simulation, observe the gear blank section in the same direction; the X-direction stress nephogram shown as Figs. 4 and 5. Fig. 4 shows that all the tooth spaces are machined from left to right in turn, and Fig. 5 shows that the machining starts from the middle of the gear blank.

The section view of the facewidth direction and the X-direction stress nephogram is indicated in Fig. 6. Fig. 6a shows the stress nephogram before gear cutting, Fig. $6 \mathrm{~b}$ shows the stress nephogram of the section from the topland, and Fig. $6 \mathrm{c}$ shows the stress nephogram of the section from the tooth space bottom.

The results indicate that the X-direction internal stress of the material adjacent to the gear cutting area changes greatly during the gear cutting. The largest $\mathrm{X}$-direction stress change occurs at the bottom of the machined tooth space, where there is little tensile stress before machining and a compressive stress of $-15 \mathrm{MPa}$ after machining. The compressive stress on the surface of the split gear blank is almost completely released during machining. The compressive stress of

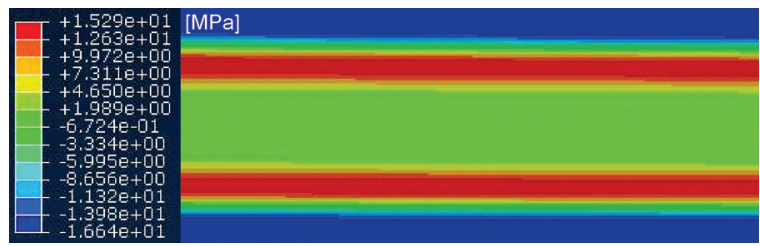

Fig. 3. X-direction stress nephogram before gear cutting

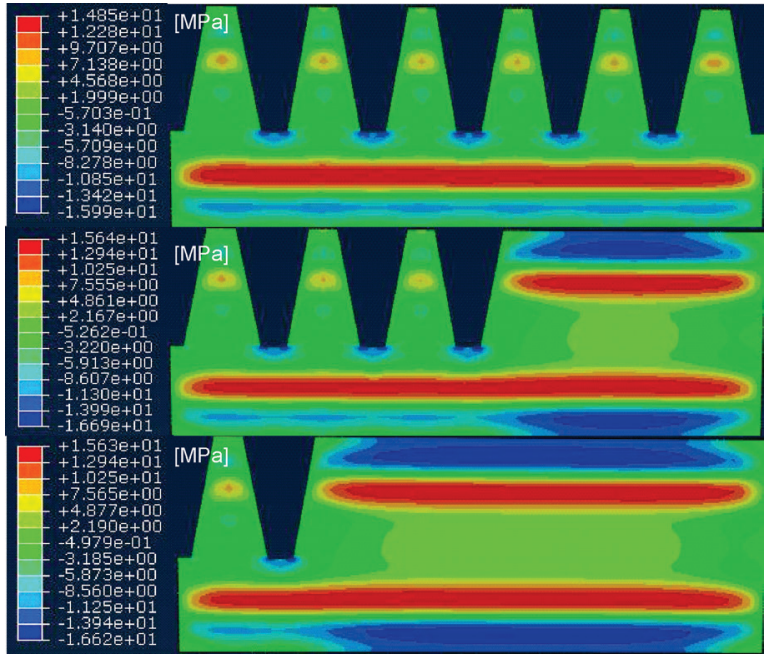

Fig. 4. X-direction stress nephogram when machining from left material near the lower surface of gear blank increases from about $-15 \mathrm{MPa}$ to $-8 \mathrm{MPa}$, and the tensile and compressive stress values inside the machined teeth decrease. The maximum tensile stress between the bottom of tooth space and the lower surface of the gear blank has little change before and after machining. The stress distribution of the top land cross-section and tooth space cross-section is basically the same

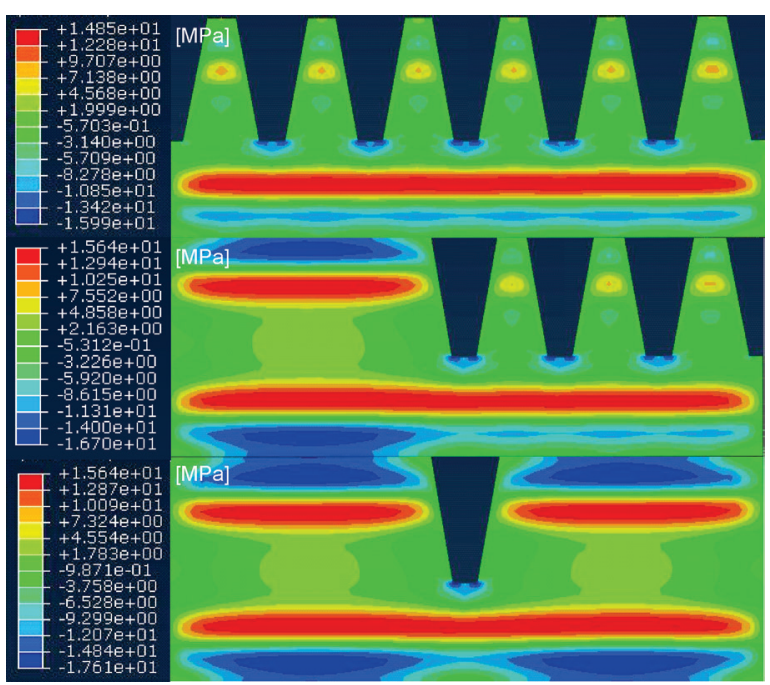

Fig. 5. X-direction stress nephogram when machining from the middle

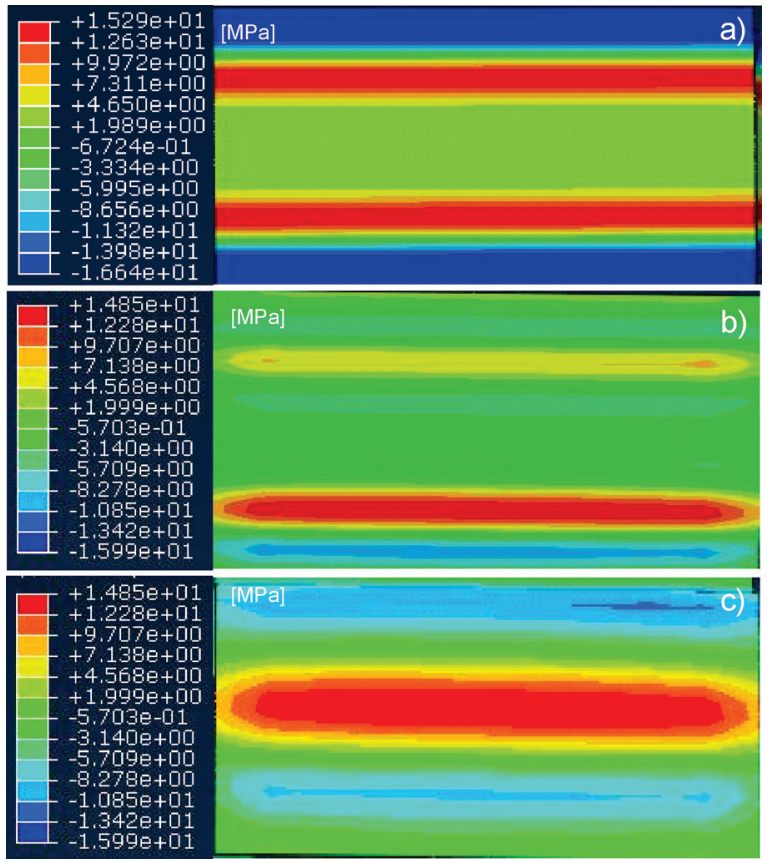

Fig. 6. X-direction stress nephogram of split gear blank along the facewidth section; a) before machining,

b) of tooth topland section, and c) of tooth space section 
in different cutting ways. The internal stress in the unmachined area does not change significantly during the tooth machining.

\subsubsection{Stress Analysis in Y-direction}

The stress analysis method in the Y-direction is similar to that in the X-direction. The finite element simulation results indicate that no matter which machining method is used, the stress change of the upper and lower surface of the gear blank is the largest, which changes from the compressive stress of $-5.9 \mathrm{MPa}$ before machining to the tensile stress after machining, and the maximum tensile stress can reach about $13.6 \mathrm{MPa}$, and the bottom of machined tooth space shows a large compressive stress.

In the machining process, the change of internal stress of the material near the gear cutting area is greater than that far away from the cutting area, but the change of Y-direction stress in the whole gear blank is less. It can be observed that the change of Y-direction stress is mainly reflected in the upper and lower surfaces of the gear blank.

\section{DEFORMATION ANALYSIS IN GEAR CUTTING}

During the gear cutting process, the material in tooth space is removed, and the stress contained in the material disappears, which is the fundamental reason for the deformation of split straight bevel gear. In this section, the deformation state of the gear blank is obtained via finite element analysis, and the deformation characteristics and law of split gear blank in gear cutting are explored. The research group's machining practice and previous study in the split straight bevel gear indicate that the bending deformation is the main deformation and the deformation is the greatest. Therefore, this section starts with the deformation analysis in Z-direction of the split gear blank and studies the deformation law of split straight bevel gear.

\subsection{Deformation Analysis in Z-direction}

In two different cutting sequences, the Z-direction displacement nephogram of gear blank is shown in Fig. 7. In the case of machining from left to right, the deformation of gear blank after machining the first two tooth spaces is only $0.03 \mathrm{~mm}$. When the gear cutting is carried out from the middle of the gear blank, the deformation suddenly increases to 0.078 $\mathrm{mm}$. When machining the middle tooth space first, the deformation is $0.048 \mathrm{~mm}$. The deformation in
Z-direction reaches $0.069 \mathrm{~mm}$ after machining all the tooth spaces in the right half. No matter which process sequence, after machining, the gear blank is bent downward along the negative direction of $\mathrm{Z}$-axis, and the maximum $\mathrm{Z}$-direction displacement in the middle of the gear blank is $0.098 \mathrm{~mm}$.

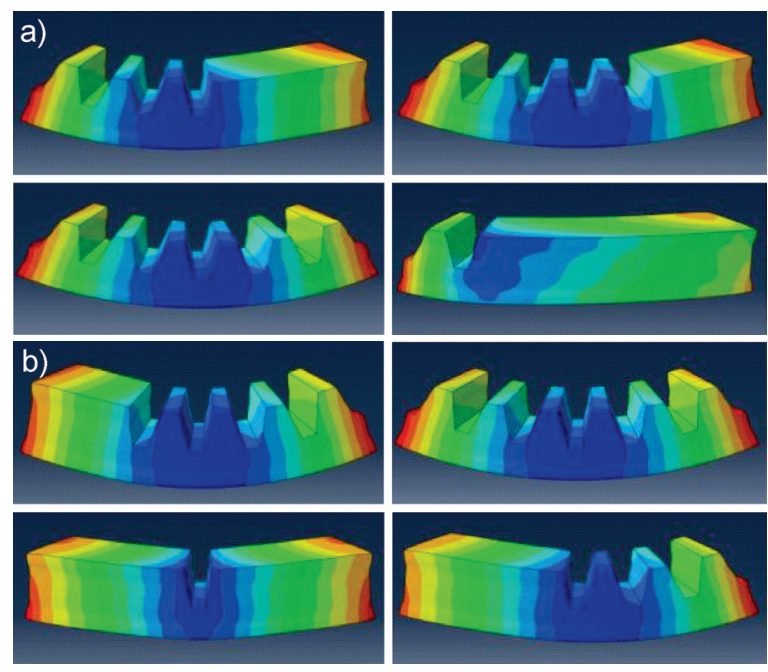

Fig.7. Z-direction displacement nephogram in different tooth cutting sequence; a) deformation when machining from left, and b) deformation when machining from middle

Thereafter, the same machining deformation analysis was carried out for $90 \mathrm{~mm}, 85 \mathrm{~mm}, 75 \mathrm{~mm}$, $70 \mathrm{~mm}$ thick gear blanks. The Z-direction deformation along the length direction of a gear blank is illustrated in Fig. 8.

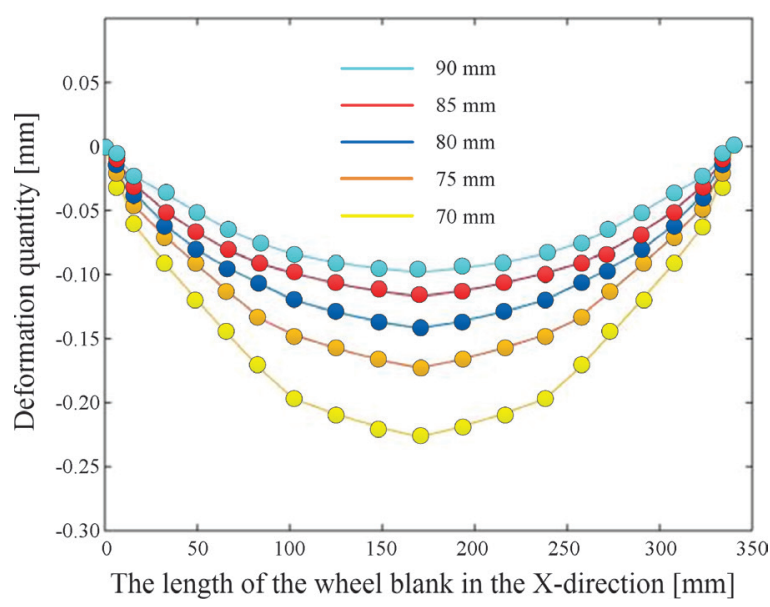

Fig. 8. Deformation in Z-direction along the length direction of gear blank with different thickness

From Fig. 8, the displacement in the Z-direction of a gear blank increases with the decrease of the thickness. The difference of the gear blank thickness 
is the same, but the difference of deformation is nonlinear, and when the gear blank thickness is less than $80 \mathrm{~mm}$, the speed of Z-direction deformation increases obviously.

In the subsequent machining and measurement experiment, five measuring lines are selected along the width direction on the bottom surface of the split straight bevel gear. The measuring lines are evenly distributed along the length direction. Points are taken every $3 \mathrm{~mm}$ on the selected measuring line, and the bottom surface coordinates are measured point by point. The comparison between the measured deformation in Z-direction and the simulation results is shown in Table 1 .

Table 1. Deformation comparison in Z-direction

\begin{tabular}{lcccc}
\hline Deformation & Outer & $\begin{array}{c}33 \mathrm{~mm} \\
\text { from outer }\end{array}$ & $\begin{array}{c}33 \mathrm{~mm} \\
\text { from inner }\end{array}$ & Inner \\
\hline Simulation $[\mathrm{mm}]$ & -0.142 & -0.133 & -0.125 & -0.118 \\
\hline Experiment $[\mathrm{mm}]$ & -0.137 & -0.130 & -0.121 & -0.115 \\
\hline
\end{tabular}

The Z-direction deformation measured by experiment along the length direction, and the simulation results are drawn as a curve, as shown in Fig. 9.

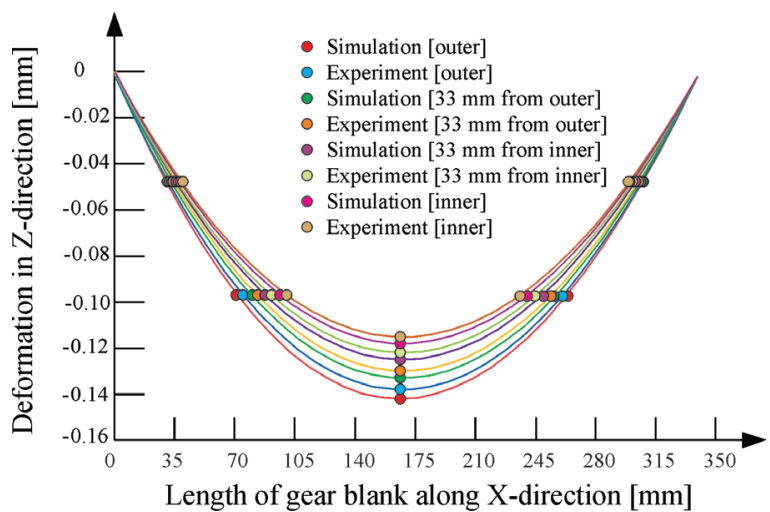

Fig. 9. Z-direction deformation at different positions along the length of gear blank

From Table 1, the deformation results obtained by finite element simulation are slightly greater than those measured in practice, and the relative errors of the two results at different positions are less than $3.6 \%$. From Fig. 9, it can be found that although the deformation of the gear blank decreases gradually from the wider end of a single tooth (an outer) to the narrower end of a single tooth (an inner), the deformation form remains unchanged, and the deformation in the middle of the length direction is obvious. The error between the experimental and simulation results is small, which verifies the correctness of the simulation model.

\subsection{Deformation Analysis in X-direction}

By analysing the displacement nephogram in the $\mathrm{X}$-direction of the split straight bevel gear, it can be found that the upper surface is in a compression state, the lower surface is in a tensile state, and the deformation in X-direction is symmetrical. With the same gear blank parameters as before, the maximum absolute value of the $\mathrm{X}$-direction displacement on the upper surface of finished gear blank is $0.052 \mathrm{~mm}$, while that on the lower surface is $0.033 \mathrm{~mm}$. The deformation process is different in different machining sequence, but the deformation mode and amount of the two methods are the same after machining. The absolute displacement in the X-direction of the upper and lower surface of the gear blank with different thickness is drawn into a broken line diagram, as illustrated in Fig. 10.

From Fig. 10, it can be observed that when the gear blank thickness decreases gradually, the displacement in the X-direction of the upper surface increases gradually, and the displacement change speed increases gradually. The X-direction displacement of the lower surface decreases with the decrease of gear blank thickness, and the displacement is obviously less than that of the upper surface. The displacement in the X-direction is less than that in the Z-direction.

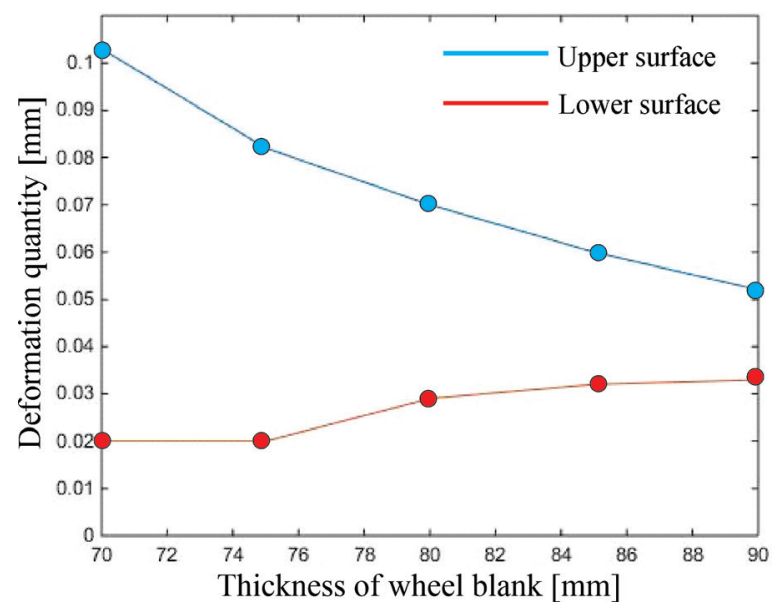

Fig. 10. X-direction deformation of upper and lower surfaces with different thickness

\subsection{Deformation Analysis in Y-direction}

By analysing the Y-direction displacement nephogram of split straight bevel gear, it can be found that in the two different machining processes, the displacement generally presents a negative direction along the Y-axis, and the displacement is almost zero on the 
lower surface, and increases gradually from the lower surface to the upper surface. In addition, during the machining process, the machined top land indicates a large negative displacement, and the maximum negative displacement of the unprocessed area is concentrated in an outer of gear blank. With the continuous machining, the negative displacement of the gear blank along the Y-direction increases gradually. After machining, the maximum negative displacement in the Y-direction is at the tooth top of the left and right ends of gear blank, and the maximum negative displacement of upper surface is $0.029 \mathrm{~mm}$.

When the only thickness of split gear blank is changed, the deformation form of the gear blank in the Y-direction will not change, but the displacement value in the Y-direction will change. The relationship between the absolute value of the maximum displacement in the Y-direction, and the gear blank thickness is drawn into a broken line diagram, as shown in Fig. 11. It can be found from Fig. 11 that with the gradual decrease of gear blank thickness, the displacement of the upper surface in the Y-direction gradually increases. In the machining process, the deformation in Y-direction is less than that in the Xand Z-directions. After machining, the deformation in the Z-direction is the largest, followed that of the $\mathrm{X}$-direction.

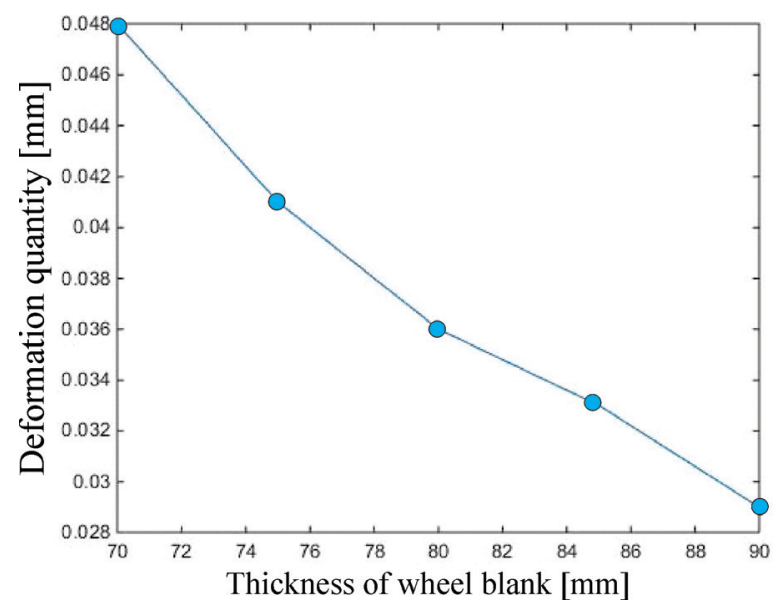

Fig. 11. Y-direction displacement of gear blank with different thickness

It is also found that the machining deformation of split straight bevel gear is not affected by the gear cutting sequence. The deformation in the Y-direction of the gear blank is slightly different in the facewidth direction, and the deformation at outer is slightly greater than that at an inner. The deformation in Y-direction is symmetrical to the middle of the length direction, the deformation of the upper surface at the left and right ends is the most obvious, and the deformation in the middle of gear blank is little.

The subsequent experimental data indicate that the diameter of the inner and outer circle has been increasing during the machining process. The diameter of the inner and outer circle increases about $0.070 \mathrm{~mm}$ after the machining, that is, the deformation of gear blank along the negative direction of the Y-axis is about $0.035 \mathrm{~mm}$. The experimental results are consistent with the finite element analysis.

\section{EXPERIMENT}

The material and size of the experimental gear blank are the same as that of the simulation model. The inner diameter of the split gear blank is $1000 \mathrm{~mm}$, the outer diameter is $1200 \mathrm{~mm}$, and the angle between the left and right end plane of the gear blank is $36^{\circ}$.

Experimental design: firstly, the outer surface of the split gear blank is machined, and the initial measurement of the gear blank is carried out in the coordinate measuring machine. The measurement items include the flatness of the bottom surface, the verticality of the left and right end faces, the diameter of the inner and outer circle, and the angle between the left and right end faces. Thereafter, the first tooth space in the middle is machined, and the second measurement is carried out after the machining. Next, several tooth spaces on the right side are machined one at a time, and the third measurement is conducted. Finally, the left half of the split gear blank is machined, and the fourth measurement is conducted.

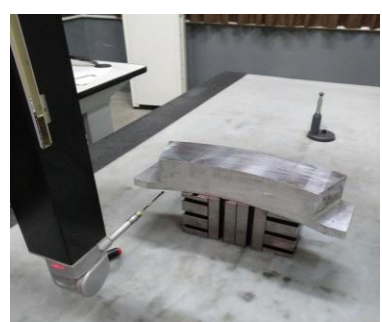

Fig. 12. First measurement

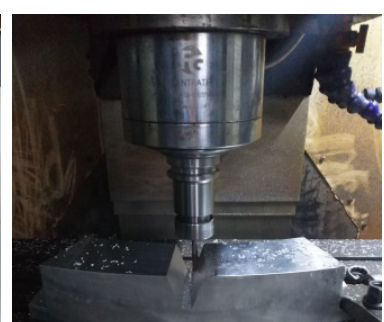

Fig. 13. Machining the 1 st tooth space
Fig. 12 shows the first measurement after the split gear blank is ready. Fig. 13 shows the machining of the first tooth space, and Fig. 14 shows the second measurement after machining the first tooth space. Fig. 15 shows the machining of the remaining tooth spaces on the right side.

Fig. 16 shows the third measurement. Fig. 17 shows the machining of the remaining tooth spaces on 
the left side, and Fig. 18 shows the fourth measurement. The measurement results are illustrated in Table 2.

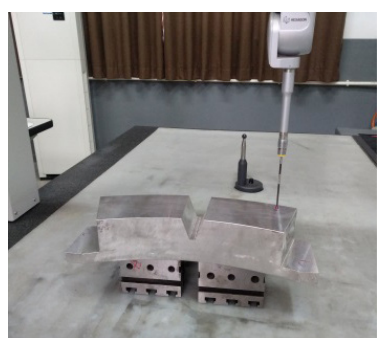

Fig. 14. Second measurement

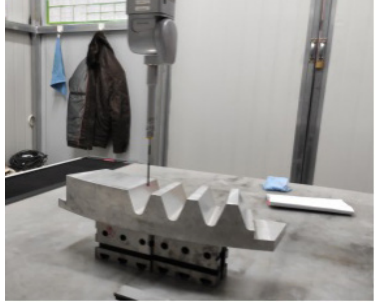

Fig. 16. Third measurement

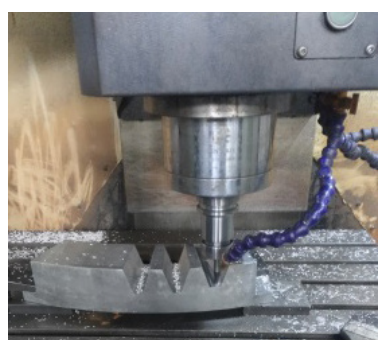

Fig. 15. Machining the right half tooth spaces

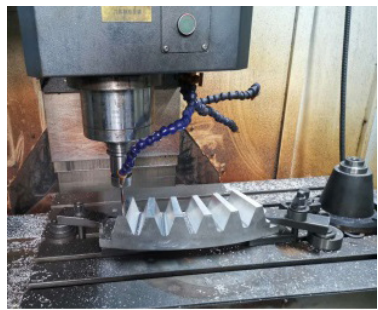

Fig. 17. Machining the left half tooth spaces

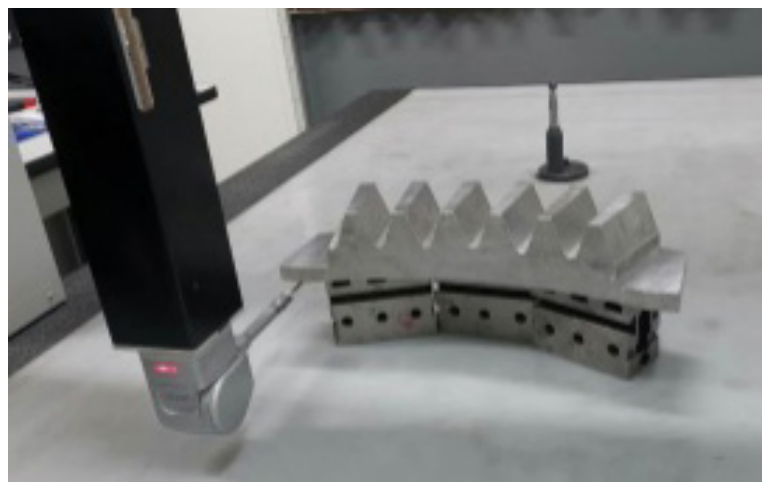

Fig. 18. Fourth measurement

In the first measurement, the gear-cutting process has not been done, so the measurement data in Table 2 is sparse. However, with the continuous machining, the shape and position tolerance and inner and outer diameter of the gear blank have changed significantly.
The angle between the left and right end faces decreases continuously during the machining; the angle after machining is reduced by $0.02^{\circ}$ compared with that before machining. It is obvious that the curvature of the gear blank is reduced, and the opening deformation occurs. After machining, the diameters of the inner and outer circle increase by about $0.07 \mathrm{~mm}$. This indicates that the deformation of the gear blank is about $0.035 \mathrm{~mm}$ along the negative direction of the Y-axis in Fig. 7. The perpendicularity tolerance of the left and right ends of gear blank to its bottom surface has been increased slightly, and the flatness of bottom surface also continues to increase in the machining process, and the flatness tolerance is far greater than its perpendicularity tolerance.

\section{CONCLUSION}

The main research results and conclusions are as follows:

1. The finite element model for the deformation prediction of the split straight bevel gear is established by the birth and death element technology, and the results of finite element calculation are in good agreement with the experimental. The finite element simulation can effectively predict the machining deformation of the split straight bevel gear caused by the residual stress.

2. In the process of gear cutting, the change of initial residual stress near the upper and lower surfaces is the greatest, and the change and redistribution of stress is independent of the cutting tooth sequence. The internal stress change near the cutting area is greater than that far away from the cutting area. In an inner of the machined tooth, the tensile and compressive stress in X-direction decreases obviously, and the stress in Y-direction changes little. The performance and change of Z-direction stress in the whole machining process are relatively minor.

3. After gear cutting, the deformation of the split straight bevel gear in all directions is symmetrical about the middle of its length direction. The split

Table 2. Experimental data

\begin{tabular}{lcccccc}
\hline $\begin{array}{l}\text { Measuring } \\
\text { order }\end{array}$ & $\begin{array}{c}\text { Flatness of bottom } \\
\text { surface [mm] }\end{array}$ & $\begin{array}{c}\text { Perpendicularity of left } \\
\text { end plane [mm] }\end{array}$ & $\begin{array}{c}\text { Perpendicularity of } \\
\text { right end plane [mm] }\end{array}$ & $\begin{array}{c}\text { Outer diameter } \\
{[\mathrm{mm}]}\end{array}$ & $\begin{array}{c}\text { Inner diameter } \\
{[\mathrm{mm}]}\end{array}$ & $\begin{array}{c}\text { Angle between two } \\
\left.\text { end planes [ }{ }^{\circ}\right]\end{array}$ \\
\hline 1 st & 0.038 & 0.016 & 0.016 & 1200.001 & 1000.001 & 36.009 \\
\hline $2^{\text {nd }}$ & 0.077 & 0.019 & 0.017 & 1200.028 & 1000.002 & 36.005 \\
\hline $3^{\text {rd }}$ & 0.121 & 0.026 & 0.025 & 1200.049 & 1000.049 & 35.996 \\
\hline $4^{\text {th }}$ & 0.161 & 0.031 & 0.028 & 1200.072 & 1000.071 & 35.989 \\
\hline
\end{tabular}


gear blank mainly presents a bending deformation state, and the tooth-cutting sequence will not affect the final deformation result. In the $\mathrm{XOZ}$ plane, the Z-direction bending deformation in the middle of split straight bevel gear is the largest. In the XOY plane, the Z-direction deformation near an outer is larger than an inner, and the difference of deformation is especially obvious in the middle of the X-direction. The X-direction deformation of the split straight bevel gear basically does not change in the facewidth direction, and the closer to the middle of length direction, the smaller the deformation is. The deformation in Y-direction is smaller in the middle position, the deformation is slightly different in facewidth direction, and the deformation at an outer is slightly greater than that at an inner.

\section{ACKNOWLEDGEMENTS}

This work was supported by the National Natural Science Foundation of China (No. 51775171).

\section{REFERENCES}

[1] Zhang, F.S., Xu, M.N., Zhang, B., Wang, J.S. (2017). Machining and Modification of the Large Modulus Straight Bevel Gear. Machinery Design and Manufacture, no. 2, p. 1-4, (in Chinese)

[2] Qi, Z.C., Wang, X.X., Chen, W.L. (2019). A new forming method of straight bevel gear using a specific die with a flash. The International Journal of Advanced Manufacturing Technology, vol. 100, p. 3167-3183, D0l:10.1007/s00170-018-2862-4.

[3] Cao, X.M., Sun, N., Deng, X.Z. (2016). Design for straight bevel gear based on low installation error sensitivity and experiment tests. Journal of Aerospace Power, no. 1, p. 227-232, D0I:10.13224/j.cnki.jasp.2016.01.029. (in Chinese)

[4] Yan, P.Q., Lu, W.Z., Zhang, D., Liu, S., Pan, H.F., Zuo, D.W. (2015). Case-based reasoning method and realization of design system for large gear ring processing method. Machine Building and Automation, vol. 44, no. 6, p. 15-17, D0I:10.19344/j.cnki.issn1671-5276.2015.06.004. (in Chinese)

[5] Zhang, J.Q., Zhang, Z.Y., Zhang, Y.G., Fu, Y.X. (2014). Design and application of manufacturing process of large-scale spiral bevel gear. Manufacturing Technology and Machine Tool, no. 5, p. 84-86, Dol:10.3969/j.issn.1005-2402.2014.05.030. (in Chinese)

[6] Kang, Z.Z., Teng, L.X. (1998). Manufacturing technology of split large gear. Machinery, no. 1, p. 27-28.

[7] Cheng, Q.L., Ke, Y.L., Dong, H.Y., Bi, Y.B.; Huang, Z.G. (2007). Distortion prediction for milling process of aerospace monolithic components. Journal of Zhejiang University (Engineering Science), vol. 41, no. 5, p. 799-803, DOI:10.3785/j.issn.1008-973X.2007.05.020. (in Chinese)

[8] Nasr, Mohamed N.A. (2017). On the role of different strain components, material plasticity, and edge effects when predicting machining-induced residual stresses using finite element modeling. Journal of Manufacturing Science and Engineering, vol. 139, no. 7, art. ID 071014, DOI:10.1115/1.4036122.

[9] Amouzegar, H., Schafer, B.W., Tootkaboni, M. (2016). An incremental numerical method for calculation of residual stresses and strains in cold-formed steel members. ThinWalled Structures, vol. 106, p. 61-74, D0l:10.1016/j. tws.2016.03.019.

[10] Liu, H.W., Zhang, Z.C., Jia, H.B., Liu, Y.J., Leng, J.S. (2020). A modified composite fatigue damage model considering stiffness evolution for wind turbine blades. Composite Structures, vol. 233, art. ID 111736, D0l:10.1016/j. compstruct.2019.111736.

[11] Gong, H. (2011). Research on Evolution and Evaluation Model of Residual Stress in Aluminum Alloy Thick Plate. PhD Thesis. Central South University: Changsha, (in Chinese)

[12] Sun, J., Ke, Y.L. (2005). Study on machining distortion of unitization airframe due to residual stress. Journal of Mechanical Engineering, vol. 41, no. 2, p. 117-122, DOI:10.3901/jme.2005.02.117. (in Chinese)

[13] Wu, H.B. (2008). Numerical Simulation and Experimental Study on Milling Deformation of Aviation Frame Integral Structure. PhD Thesis. Zhejiang University, Hangzhou. (in Chinese)

[14] Lu, D. (2007). Deformation Prediction and Fixture Layout Optimization of Aerospace Monolithic Components. PhD Thesis. Shandong University, Jinan. (in Chinese)

[15] Zhou, W.C. (2015). Research on Machining Distortion of Thin-Walled Rotary Part. MSc Thesis. Nanjing University of Aeronautics and Astronautics, Nanjing. (in Chinese)

[16] Huang, X.M. (2015). Deformation Mechanism and Prediction of Aluminum Alloy Monolithic Component in the Milling. PhD Thesis. Shandong University, (in Chinese)

[17] Nervi, S. (2005). A mathematical model for the estimation of effects of residual stresses in aluminum parts, PhD Thesis. Washington University. St. Louis.

[18] Wu, Q., Li, D.P., Zhang, Y.D. (2016). Detecting milling deformation in 7075 aluminum alloy aeronautical monolithic components using the quasi-symmetric machining method. Metals, vol. 6, no. 4, art. ID 80, D0I:10.3390/met6040080.

[19] Zhang, J.W., Yu, L.M., Liu, Y.C., Ma, Z.Q., Li, H.J., Liu, C.X., Wu, J.F., Ma, J.G., Li, Z.I. (2018). Analysis of the effect of tungsten inert gas welding sequences on residual stress and distortion of CFETR vacuum vessel using finite element simulations. Metals, vol. 8, no. 11, art. ID 912, D0l:10.3390/met8110912.

[20] Keith, A.Y., Sebastian, N., Barna, S. (2005). Machining-Induced Residual Stress and Distortion. Washington University, St. Louis.

[21] Ratchev, S., Liu, S., Huang, W., Becker, A.A. (2006). An advanced FEA based force induced error compensation strategy in milling. International Journal of Machine Tools and Manufacture, vol. 46, no. 5, p. 542-551, D0l:10.1016/j. ijmachtools.2005.06.003.

[22] Bremec, B., Kosel, F. (2002). Determination of the buckling loads of circular annular plates in the elastic-plastic region. Strojniški vestnik - Journal of Mechanical Engineering, vol. 48, no. 11, p. 613-620. 